\title{
Modification of physical properties of poly(L-lactic acid) by addition of methyl- $\beta$-cyclodextrin
}

\author{
Toshiyuki Suzuki ${ }^{1,2}$, Ayaka $^{2}{ }^{2}$, Yoshihisa Takada ${ }^{2}$, Hiroki Uehara ${ }^{2}$, Takeshi Yamanobe ${ }^{* 2}$ \\ and Keiko Takahashi ${ }^{3}$
}

\author{
Full Research Paper \\ Address: \\ ${ }^{1}$ Perkin-Elmer Japan Co. Ltd., 134 Godo-cho, Hodogaya-ku, \\ Yokohama-shi 240-0004, Japan; Fax: +81-45-339-5861, Gunma \\ University, 1-5-1 Tenjin-cho, Kiryu-shi, Gunma 376-8515, Japan; Fax: \\ +81-277-30-1331 and ${ }^{3}$ Tokyo Polytechnic University, 1583 liyama, \\ Atsugi 243-0297, Japan; Fax +81-46-242-3000 \\ Email: \\ Toshiyuki Suzuki - toshiyuki.suzuki@perkinelmer.com; \\ Takeshi Yamanobe* - yamanobe@gunma-u.ac.jp; Keiko Takahashi - \\ takahasi@chem.t-kougei.ac.jp \\ * Corresponding author \\ Keywords: \\ crystallinity; DSC; methyl- $\beta$-cyclodextrin; poly(L-lactic acid); Raman \\ spectroscopy
}

Open Access

\begin{abstract}
Poly(L-lactic acid) (PLLA) is a biodegradable plastic and one of the most famous plastics made from biobased materials. However, its physical strength is insufficient compared to general-purpose plastics. In this study, the effect of methylcyclodextrin (MeCD) addition on the structure and physical properties, especially the drawing behavior, of PLLA was investigated. Through thermal analysis, it was found that MeCD addition lowers the crystallinity and enhances the mobility of PLLA. The sample containing approximately $17 \% \mathrm{MeCD}$ was drawn to more than $1000 \%$ at $60{ }^{\circ} \mathrm{C}$, although PLLA fractured at a strain of less than $100 \%$. Differential scanning calorimetry (DSC)-Raman in situ measurements also revealed decreases in the glass transition temperature ( $\left.T_{\mathrm{g}}\right)$, cold crystallization temperature $\left(T_{\mathrm{c}}\right)$, and melting point $\left(T_{\mathrm{m}}\right)$, and improvement in structural distribution with temperature. DSCRaman measurements simultaneously supplied information about crystallinity and thermal properties. Thus, it was concluded that $\mathrm{MeCD}$ had high affinity for PLLA, and the addition of MeCD increased the amorphous component of PLLA and enhanced the drawability.
\end{abstract}

\section{Introduction}

Poly(L-lactic acid) (PLLA) has attracted attention because it is a biodegradable polymer derived from carbon-neutral resources. However, its melting point $\left(T_{\mathrm{m}}\right)$ of approximately $170{ }^{\circ} \mathrm{C}$ must

be increased because of the low thermal resistance. The melting point of the stereo complex (Sc) of PLLA and poly(D-lactic acid) (PDLA) is higher than $220^{\circ} \mathrm{C}$ [1-5], which is comparable 
to that of aromatic polyester. Many studies have been conducted for improving this thermal property using Sc [6-16].

PLLA is a brittle polymer, but the polymer should have a high toughness so that it can be used for mechanical purposes. Tensile drawing is one method of improving mechanical properties, since it effectively induces molecular orientation [17-27]. However, the brittleness of PLLA prevents drawing. To improve this, it is necessary to control the interchain interactions and lower the glass transition temperature $\left(T_{\mathrm{g}}\right)$ of the amorphous phase.

Cyclodextrins (CDs) are cyclic molecules composed of six $(\alpha)$, seven $(\beta)$, or eight $(\gamma)$ glucose units. CDs have hydrophobic cavities that can contain guest molecules and form inclusion complexes (ICs). ICs with $\alpha$-CD accelerate the nucleation and crystallization of poly( $\varepsilon$-caprolactone), poly(ethylene glycol), poly(butylene succinate), and poly(3-hydroxybutyrate) by acting as a nucleation agent [28-33].

Several attempts have been made to form ICs between CDs and PLLA, and their structures and physical properties have also been analyzed [34-36]. It has been reported that the loss factor peak, $\tan \delta$, shifted to a higher temperature because of IC formation [37]. In the solid ICs of CDs and PLLA, the CD-CD interactions are dominant over the PLLA-PLLA interactions. Therefore, by forming an IC, CD increases the $T_{\mathrm{g}}$ of PLLA, which is not desirable for the improvement of mechanical properties. Since this results from strong $\mathrm{CD}-\mathrm{CD}$ interactions, a modified
CD may improve the mechanical properties of PLLA. Methyl$\beta$-cyclodextrin (MeCD) is soluble in chloroform, as is PLLA, and the affinity of MeCD for PLLA may be sufficient to improve the mechanical properties of PLLA.

In order to analyze the interchain interactions of polymers, it is necessary to acquire information about their thermal properties and structure. Differential scanning calorimetry (DSC) is a very useful method for analyzing the thermal properties such as $T_{\mathrm{g}}$ and cold crystallization temperature $\left(T_{\mathrm{c}}\right)$. However, it does not provide details about the structural change. On the other hand, Raman spectroscopy reveals the vibrational states of functional groups, but not thermal properties because irradiation affects the sample temperature [38]. For exact and expeditious structural analysis, it is important to determine simultaneously the thermal properties and the local structure $[39,40]$. Recently, DSC and Raman spectroscopy (DSC-Raman), which simultaneously measure thermal behavior and Raman vibrational states, was developed. The purpose of this study is to investigate the effects of MeCD on the local structure and physical properties of PLLA by DSC-Raman spectroscopy.

\section{Results and Discussion Thermal properties}

Figure 1 shows the thermogravimetric analysis (TGA) results for MeCD, PLLA, PL-MCD83, PL-MCD67, and PL-MCD50. PL-MCD83, PL-MCD67, and PL-MCD50 refer to the mixtures of MeCD and PLLA with 83, 67, and 50 wt \% of PLLA, respectively. Below $200{ }^{\circ} \mathrm{C}$, a weight loss is observed, except for

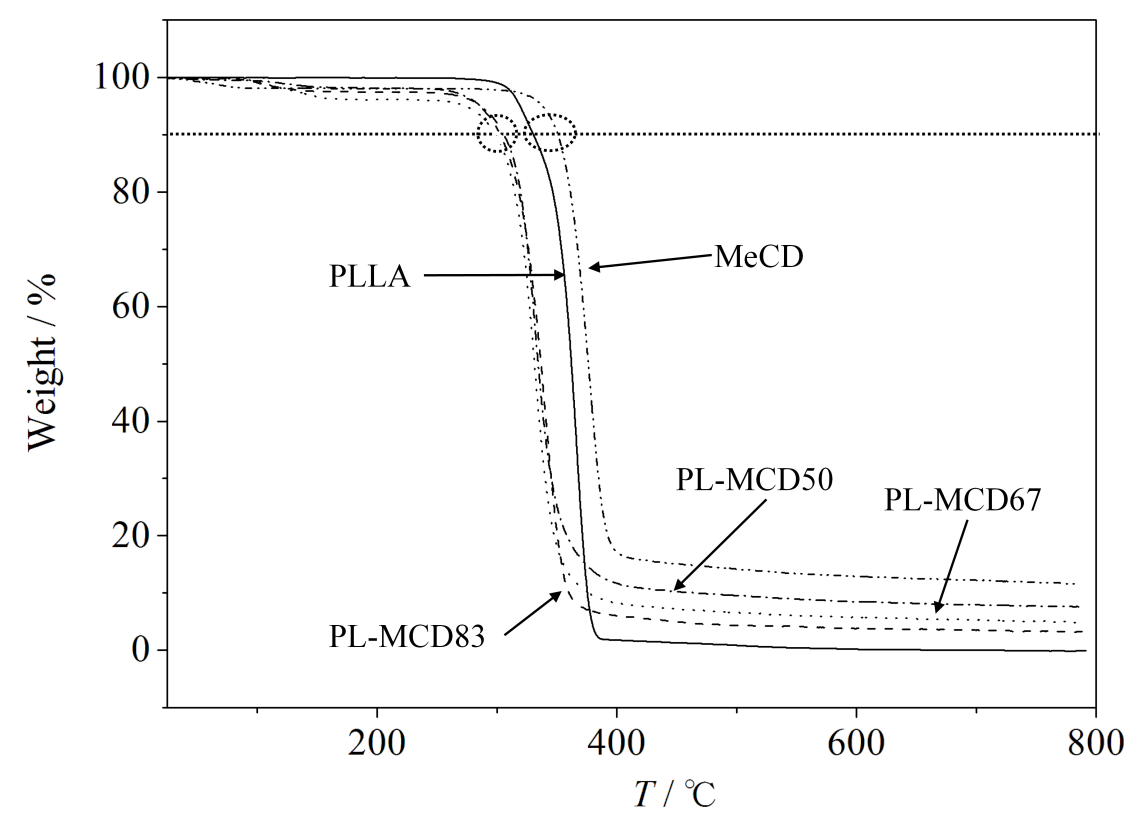

Figure 1: Thermo-gravitometry for PLLA, PL-MCD83, PL-MCD67, PL-MCD50 and MeCD. 
PLLA. For MeCD, this weight loss arises from dehydration $[41,42]$. For PL-MCD samples, the weight loss begins at higher temperatures than for MeCD. The weight loss is caused by desorption of chloroform from the MeCD cavity. This weight loss may not be observed if PLLA is included in the MeCD cavity, indicating that an IC with PLLA is not formed.

The $10 \%$ weight loss temperatures for PL-MCD50, 67, and 83 are lower than those of PLLA and MeCD. Since the decomposition is affected by crystallinity, the mixing of $\mathrm{MeCD}$ with PLLA lowers the thermal resistance because of the increase in the amorphous phase. In other words, MeCD causes PLLA to be disordered.

Above $400{ }^{\circ} \mathrm{C}$, most samples decompose, and at $800{ }^{\circ} \mathrm{C}$, less than $12 \%$ of the residues of the decomposed samples remain. At $800{ }^{\circ} \mathrm{C}$, PLLA and MeCD had 2 and 16 wt \% of the residue, respectively. The decomposition weight loss of PLLA and $\mathrm{MeCD}$ mixture can be calculated from the linear relationship between the pure PLLA and MeCD if the interaction between $\mathrm{MeCD}$ and PLLA does not exist. Figure 2 shows the actual weight loss caused by decomposition at $800{ }^{\circ} \mathrm{C}$ and the theoretical weight loss line (the solid line). From this figure, it is clear that the actual weight loss is less than the theoretical weight loss. This means that the environment around the mixed MeCD and PLLA samples is different from that of pure PLLA and $\mathrm{MeCD}$. Since the IC between PLLA and MeCD does not form according to the above results, the environmental changes around MeCD and PLLA may be caused by their high miscibility in each other. Therefore, MeCD acts as a plasticizer for PLLA. The plasticizing effects of triacetin and oligomeric poly(1,3-butylene glycol adipate) on PLLA have been reported [43-46]. Although these plasticizers are reported to be superior to $\mathrm{MeCD}, \mathrm{MeCD}$ is a biobased material and is thus advantageous from an environmental perspective.

These TGA results show that MeCD acts as a plasticizer for PLLA, and the fraction of the amorphous phase increases. Since the $T_{\mathrm{g}}$ of the samples may be affected by the MeCD addition, DSC measurements were also carried out. Figure 3 shows the DSC curves. For PLLA, the $T_{\mathrm{g}}$ and endothermal peak of melting are observed at approximately 70 and $180{ }^{\circ} \mathrm{C}$, respectively. In addition, a slight cold crystallization is observed at approximately $120^{\circ} \mathrm{C}[15,47-49]$. Addition of MeCD alters the DSC curves. For PL-MCD83 and 67, $T_{\mathrm{g}}$ decreases to approximately $60{ }^{\circ} \mathrm{C}$; similar trends were observed for $T_{\mathrm{c}}$ and $T_{\mathrm{m}}$. For PL-MCD50, $T_{\mathrm{g}}$ and $T_{\mathrm{c}}$ are higher than those of PL-MCD67 and 83, while their $T_{\mathrm{m}}$ is approximately equal. The enthalpies of fusion for PL-MCD50, 67, and 83 are approximately equal to the enthalpies of cold crystallization. Therefore, the melting of PL-MCD50, 67, and 83 are caused by the crystals formed

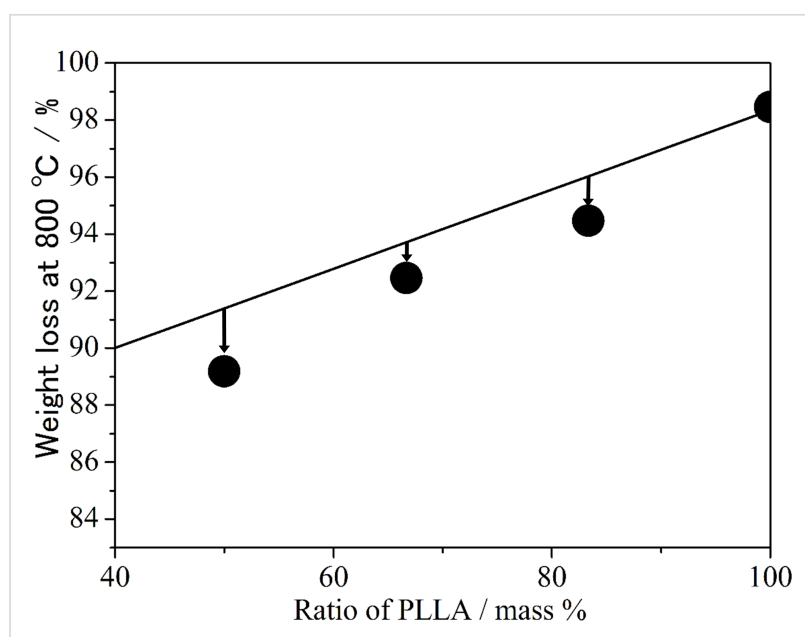

Figure 2: Observed weight loss and stoichiometric line.

through cold crystallization, and it can be concluded that PL-MCD50, 67, and 83 are amorphous. As the $T_{\mathrm{g}}$ and $T_{\mathrm{c}}$ decreased, the mobility of the amorphous phase increased through the addition of $\mathrm{MeCD}$. It has been reported that the unmodified $\alpha-C D$ accelerates the crystallization of PCL, PEG, PBS and P3HB during cooling from melts. Cooling measurements by DSC were carried out for PLLA, PL-MCD50, 67 and 83 to confirm the similar effects. However, the crystallization was not observed for PLLA, PL-MCD50, 67 and 83 with a cooling rate of $10^{\circ} \mathrm{C} \cdot \mathrm{min}^{-1}$. Therefore, MeCD does not have a potential to accelerate the crystallization of PLLA.

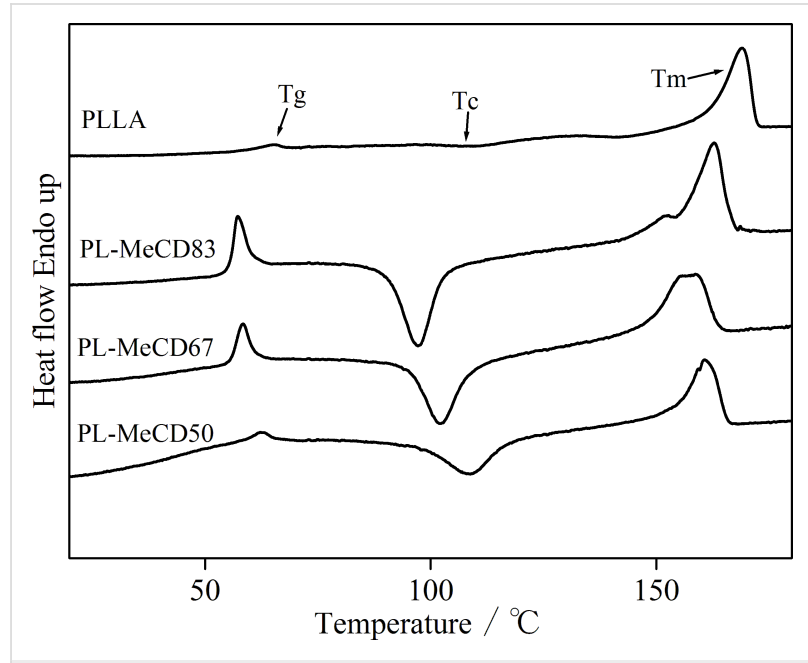

Figure 3: DSC curves for PLLA, PL-MCD83, PL-MCD67 and PL-MCD50.

\section{Tensile drawing behavior}

Figure 4 shows the stress-strain curves for the PLLA and PL-MCD samples at 25,60 , and $100{ }^{\circ} \mathrm{C}$. At $25^{\circ} \mathrm{C}$, all samples fractured at less than $20 \%$ elongation in Figure $4 \mathrm{c}$. The breaking 

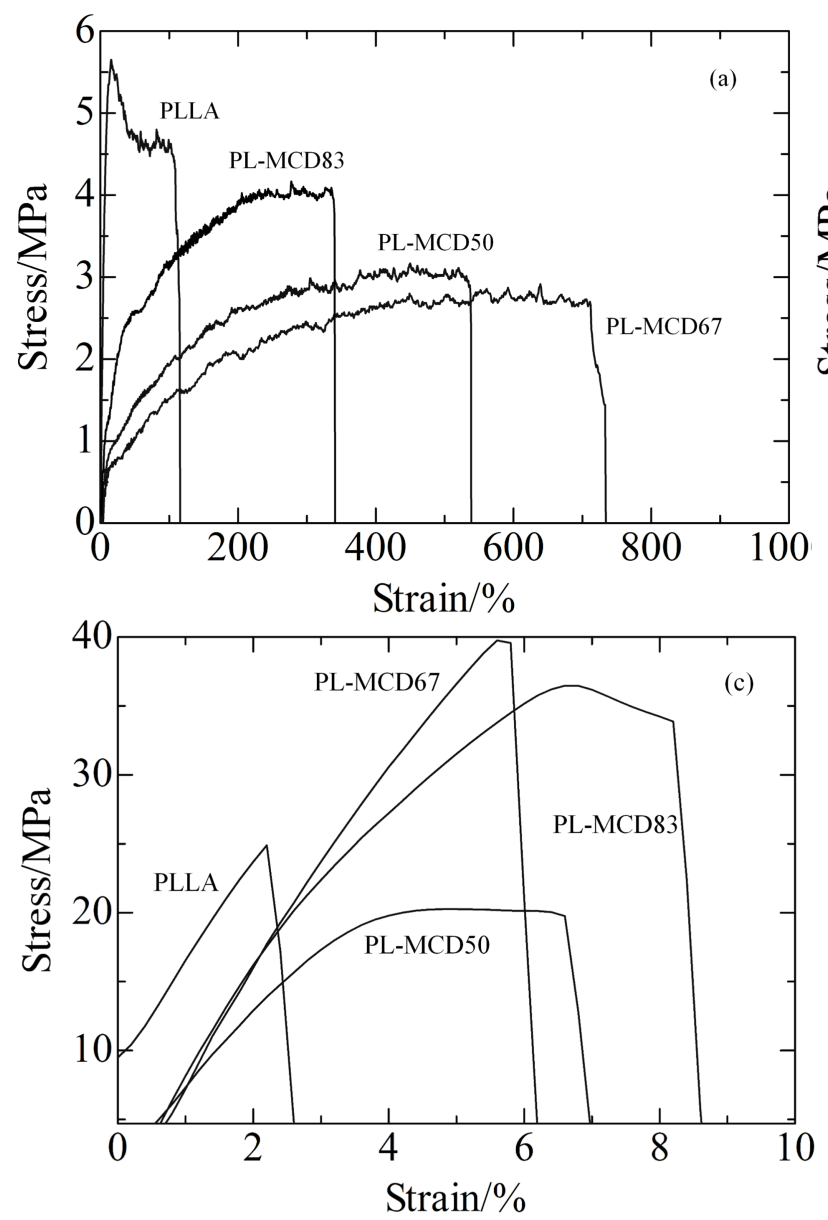

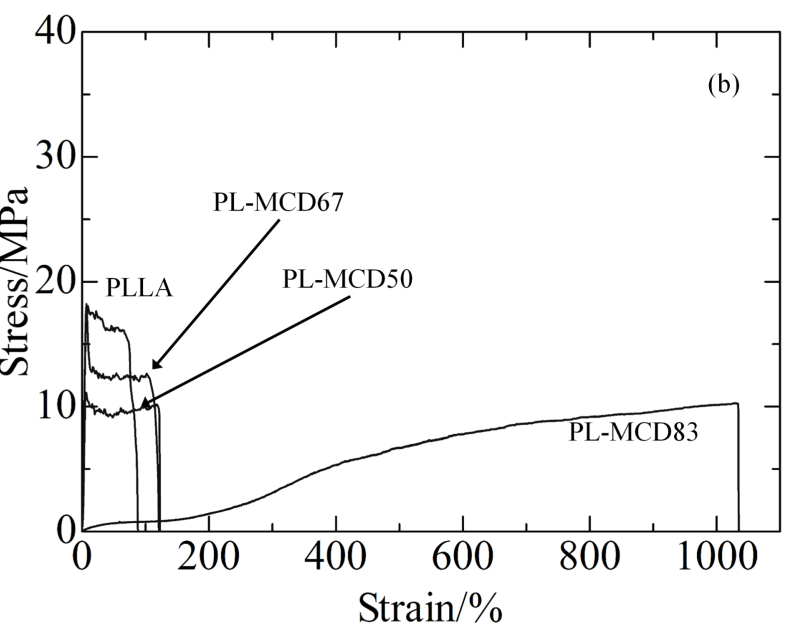

(b)

Figure 4: Stress-Strain curve for PLLA, PL-MCD50, 67 and 83 at a) $100{ }^{\circ} \mathrm{C}$, b) $60^{\circ} \mathrm{C}$ and c) $25^{\circ} \mathrm{C}$.

stress at $25{ }^{\circ} \mathrm{C}$ is the highest for all the temperatures observed. This behavior is typical for brittle plastics, indicating that the $T_{\mathrm{g}}$ of the amorphous phase is higher than $25^{\circ} \mathrm{C}$.

At $60{ }^{\circ} \mathrm{C}$, PLLA fractured at less than $100 \%$ strain, which is much larger than at $25^{\circ} \mathrm{C}$ in Figure 4b. For PL-MCD50 and 67, similar behavior to PLLA was observed. These samples exhibited yield points, followed by extensive elongation at an almost constant strain, which is typical for a tough plastic where the semicrystalline polymer shows an amorphous phase above $T_{\mathrm{g}}$. In contrast, PL-MCD83 was drawn to a maximum strain of greater than $1000 \%$ and did not exhibit a yield point. The stress is low at short elongation and increases with elongation, which is typical for elastomers. Therefore, the mechanical properties of these samples are governed by rubber elasticity. In other words, MeCD prevents PLLA crystallization and lowers the $T_{\mathrm{g}}$ for PL-MCD83. In fact, the $T_{\mathrm{g}}$ of PL-MCD83 is lowest among the samples studied. This behavior is in accord with the TGA and DSC results.
At $100{ }^{\circ} \mathrm{C}$, the stress-strain curves did not exhibit yield points except for PLLA in Figure 4a, since it contains a crystalline phase. The other samples behave as elastomers; the largest break strains are lower than those at $60^{\circ} \mathrm{C}$. This indicates that the mobility of PLLA molecules is high at $100{ }^{\circ} \mathrm{C}$ and that the tensile stress cannot propagate properly.

In addition, dynamic mechanical analysis (DMA) measurements were conducted. Figure 5 shows the temperature dependence $\tan \delta$. The peak assigned to the $T_{\mathrm{g}}$ for PLLA is approximately $70{ }^{\circ} \mathrm{C}[50]$. For PL-MCD83 and 67, it is approximately $60{ }^{\circ} \mathrm{C}$. Thus, it can be concluded that $\mathrm{MeCD}$ addition lowered the $T_{\mathrm{g}}$ 's.

\section{DSC-Raman measurements}

The Raman spectra of PLLA, PL-MCD50, 67, 83, and MeCD at $25^{\circ} \mathrm{C}$ are displayed in Figure 6 . The peak assignments of PLLA are summarized in Table 1. MeCD exhibited scattering peaks at $1457,1157,1080,857$, and $449 \mathrm{~cm}^{-1}$. High-intensity character- 


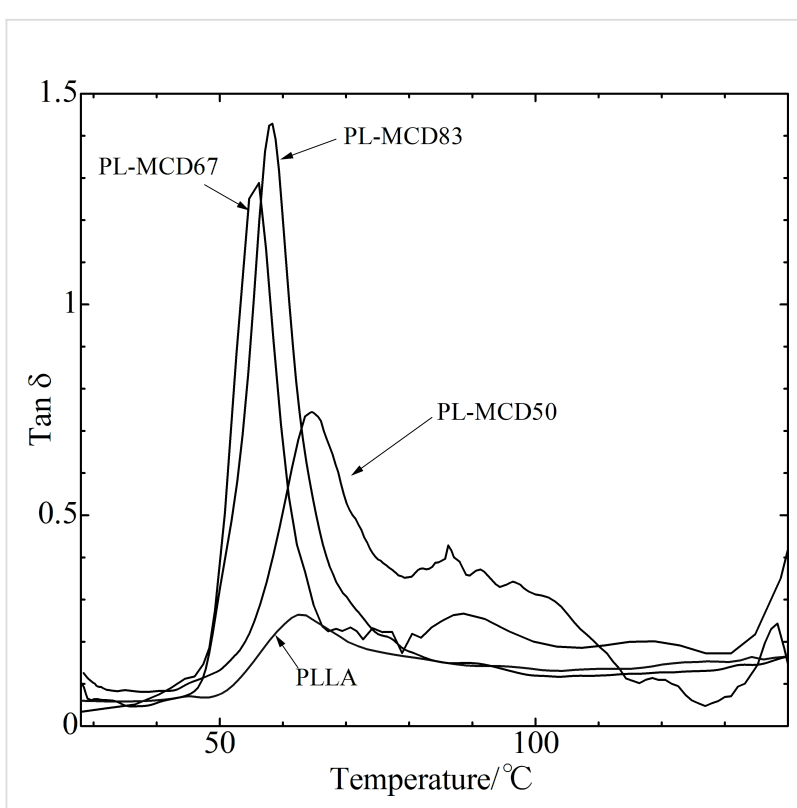

Figure 5: Temperature dependence of tanס for PLLA, PL-MCD50, PL-MCD67 and PL-MCD83.

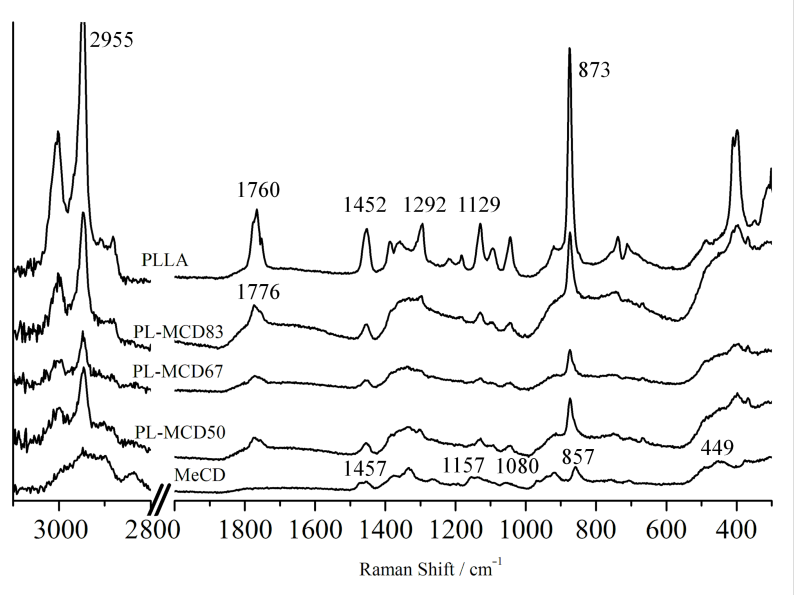

Figure 6: Raman spectra for PLLA, PL-MCD83, 67, 50 and MeCD at room temperature.

istic peaks for PLLA are at $2955 \mathrm{~cm}^{-1}(\mathrm{vCH}), 1760 \mathrm{~cm}^{-1}$ $(v \mathrm{C}=\mathrm{O}), 1452 \mathrm{~cm}^{-1}\left(\delta \mathrm{CH}_{3}\right), 1292 \mathrm{~cm}^{-1}(\delta \mathrm{CH})$, and $873 \mathrm{~cm}^{-1}$ $(\mathrm{vC}-\mathrm{C} \alpha)[51,52]$. Peaks at 857 and $449 \mathrm{~cm}^{-1}$ are characteristic for $\mathrm{MeCD}$ [53].

In the Raman spectra of PL-MCD50, 67, and 83, the PLLA peaks are clearly observed, while $\mathrm{MeCD}$ peaks are obscured. This is caused by peak overlap and weak MeCD peak intensity owing to the lower molar ratio of MeCD. Since the characteristic peak at $857 \mathrm{~cm}^{-1}$ for MeCD overlapped with the peak at $873 \mathrm{~cm}^{-1}$, it is difficult to analyze the structure of MeCD
Table 1: Peak assignment of PLLA.

\begin{tabular}{|c|c|}
\hline Peak assignment & Wave number $\left[\mathrm{cm}^{-1}\right]$ \\
\hline $\mathrm{vCH}_{3}$ as & 2998 \\
\hline $\mathrm{vCH}, \mathrm{vCH}_{3} \mathrm{~s}$ & 2945,2900 \\
\hline $\mathrm{vC}=\mathrm{O}$ & 1762 \\
\hline$\delta \mathrm{CH}_{3}$ as & 1452 \\
\hline$\delta \mathrm{CH}_{3} \mathrm{~s}, \delta \mathrm{CH}$ & $1385,1365,1292$ \\
\hline $\mathrm{rCH}$ & 1215,1180 \\
\hline $\mathrm{yCH}_{3}$ & 1129,1091 \\
\hline$v C_{\alpha}-C_{\beta}$ & 1042 \\
\hline 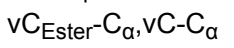 & 920,872 \\
\hline $\mathrm{yC}=\mathrm{O}$ & 735,707 \\
\hline $\mathrm{TC}-\mathrm{O}_{\mathrm{E},} \delta \mathrm{O}=\mathrm{CO}_{\mathrm{E}}$ & $510,408,394,340$ \\
\hline$\delta C C=O, y C C C$ & 305,237 \\
\hline
\end{tabular}

through this peak. Although the other characteristic peak of $\mathrm{MeCD}$ at $449 \mathrm{~cm}^{-1}$ is not typically employed, its intensity can be used to measure the state of MeCD, since PLLA does not exhibit a peak in this region.

The peak at $1760 \mathrm{~cm}^{-1}$ for PLLA shifts to a higher wavenumber by approximately $6 \mathrm{~cm}^{-1}$ because of MeCD addition. This peak shift is likely caused by the interaction between PLLA and $\mathrm{MeCD}$. Compared to the amorphous phase, the wavenumber of the Raman peak for the crystalline phase is lower by $6 \mathrm{~cm}^{-1}$ [54]. Therefore, the addition of MeCD induces the amorphous phase of PLLA. The shift of the peak at $1760 \mathrm{~cm}^{-1}$ indicates the change in crystallinity. For other peaks, a peak shift was insignificant. Although MeCD is mixed with PLLA, the IC was seemingly not formed. As in the tensile drawing test, PL-MCD83 exhibited the largest strain. Its structure was investigated through DSC-Raman measurements.

Figure 7 shows the Raman spectrum of PL-MCD83 at a temperature close to its $T_{\mathrm{g}}, T_{\mathrm{c}}$, and $T_{\mathrm{m}}$. The peak intensities at 1760 and $873 \mathrm{~cm}^{-1}$, which are the characteristic peaks of PLLA, decreased as the temperature increased. In addition, both peaks broadened with temperature, which is remarkable above $T_{\mathrm{c}}$. Peak broadening and decrease in the peak intensity were also observed for other peaks.

The peak position, intensity, and width provide important structural information. Figure 8 shows the stacked line profiles of the Raman spectra of PL-MCD83 for the characteristic peak of PLLA at $873 \mathrm{~cm}^{-1}$. The horizontal dotted line represents the top of the peak at $873 \mathrm{~cm}^{-1}$. In this figure, the white region indicates high intensity. Therefore, the vertical width of the white region corresponds to the peak width. As the temperature increases from room temperature to $60^{\circ} \mathrm{C}$, the peak width either 


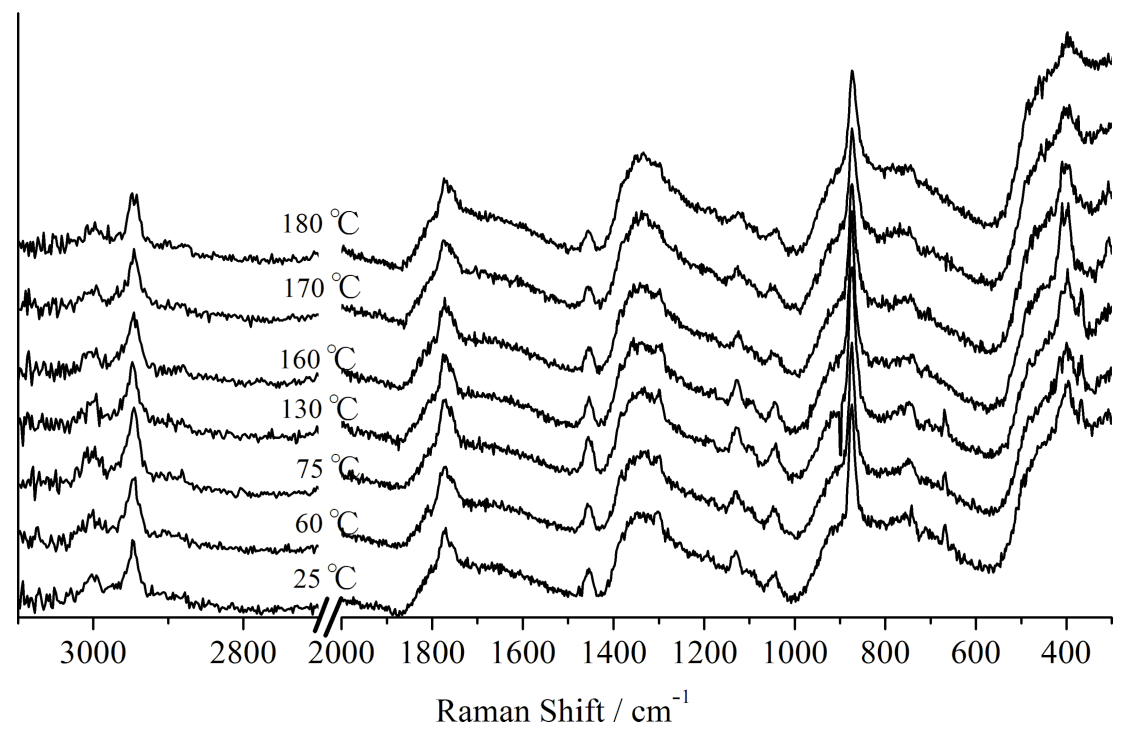

Figure 7: Temperature dependence of Raman spectrum of PL-MCD83.

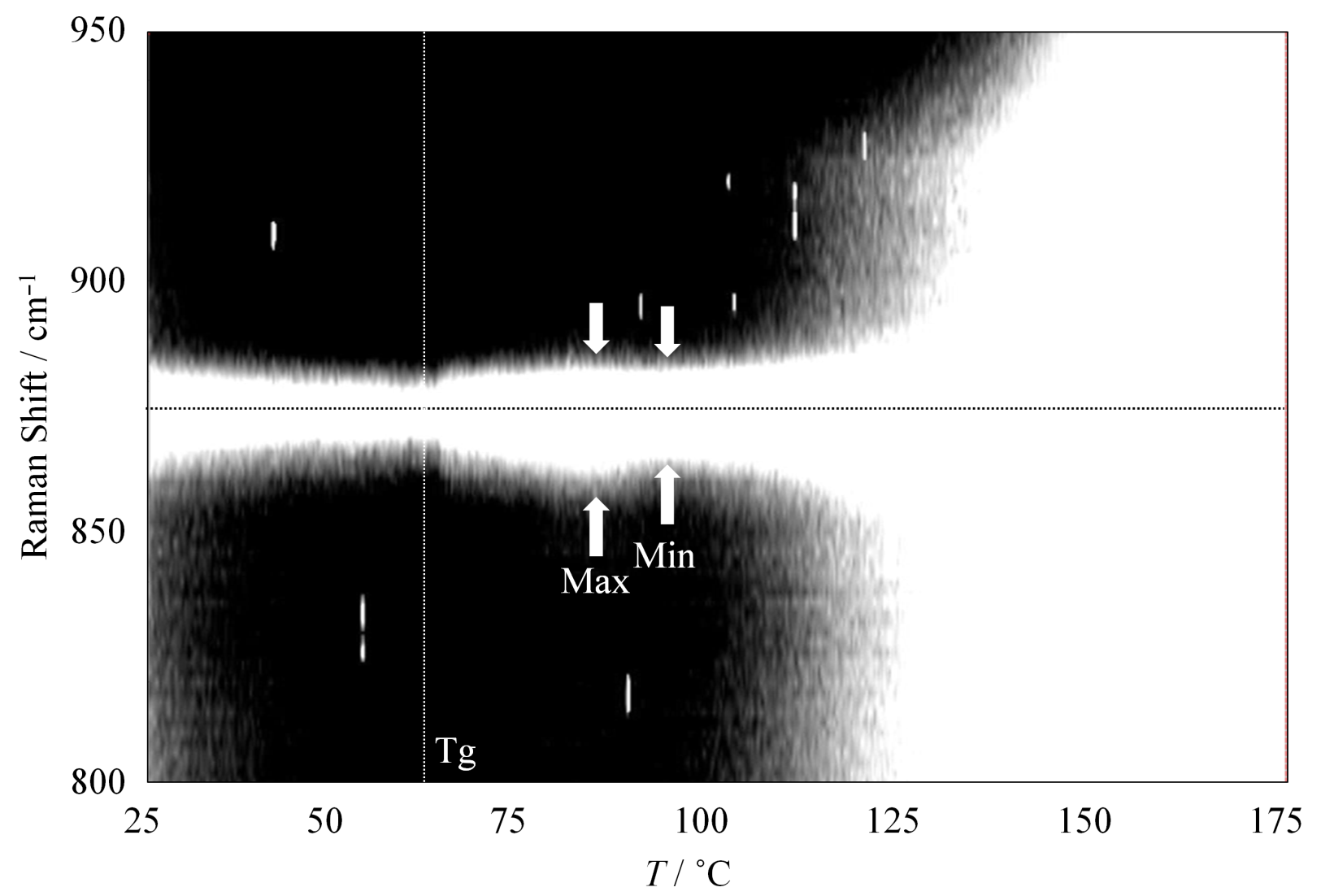

Figure 8: Stacked line profiles of Raman spectra of PL-MCD83 for the characteristic peak of PLLA at $873 \mathrm{~cm}^{-1}$.

remains nearly constant or slightly decreases. Above the $T_{\mathrm{g}}$, the peak width increases and reaches a maximum at $80{ }^{\circ} \mathrm{C}$. Between the $T_{\mathrm{g}}$ and $80{ }^{\circ} \mathrm{C}$, the activation of segmental motion induces local structural distribution. In this temperature range, PLLA is in the amorphous state, and the molecular mobility is suitable to be drawn. Therefore, the largest strain was obtained 
for PL-MCD83 in this temperature range. Above $80{ }^{\circ} \mathrm{C}$, the peak width begins to decrease, passes the minimum at approximately $100^{\circ} \mathrm{C}$, and then increases again. This sample undergoes cold crystallization at approximately $100^{\circ} \mathrm{C}$, causing peak narrowing at above $80{ }^{\circ} \mathrm{C}$. The produced crystalline phase prevents drawing above $T_{\mathrm{c}}$, where the peak width monotonically increases. The peak broadening indicates that the local structure of the sample is disturbed by the thermal energy. Thus, in addition to the thermal properties, the local structural distribution can also be deduced from the DSC-Raman measurements. Furthermore, the tensile drawing behavior can be explained through molecular mobility and local structural distribution.

\section{Transition analysis by continuous intensity change of Raman spectrum}

Since the peak area is proportional to the width and intensity, the peak intensity is also a good indicator for the local structure. Principle components analysis (PCA) is one of the most wellknown techniques for analyzing intensity change in continuous data [55,56]. DSC-Raman results can be divided into elements of time, temperature, Raman scattering, and heat flow [57,58]. Since there was a one-to-one correspondence between the time and temperature in DSC-Raman, parameters extracted from temperature or time and intensities of scattering can be applied to transition analysis. This method has the advantage of being able to analyze the precise temperature dependence of each peak, and by extension, each functional group.

Figure 9 shows the PCA results for PLLA from simple integration of its characteristic peaks. The peak intensity at $2955 \mathrm{~cm}^{-1}$ is nearly constant from room temperature to $70{ }^{\circ} \mathrm{C}$. Above $70{ }^{\circ} \mathrm{C}$, the intensity decreases suddenly. This decrease corresponds with the $T_{\mathrm{g}}$. In the DSC curve, the $T_{\mathrm{g}}$ of PLLA appeared as a slight baseline change because this sample was not amorphous. In Figure 9, the intensity change at $T_{\mathrm{g}}$ is clear for PLLA. Therefore, PCA analysis of DSC-Raman measurements can detect thermal changes with high sensitivity.

The peak intensity decreases between 70 and $120^{\circ} \mathrm{C}$. Above $120^{\circ} \mathrm{C}$, the intensity increases slightly, which corresponds to cold crystallization. Thus, the behavior of the peak intensity is similar to the DSC heat flow. The intensity change of other peaks is similar to that of the peak at $2955 \mathrm{~cm}^{-1}$.

Figure 10 shows the temperature dependence of the peak intensities for PL-MCD83. The peak intensities decreased clearly at approximately $60{ }^{\circ} \mathrm{C}$, which corresponds to the $T_{\mathrm{g}}$. The $T_{\mathrm{g}}$ of this sample is lower than that of PLLA, which is in accord with the deterioration of the crystalline phase from $\mathrm{MeCD}$ addition.

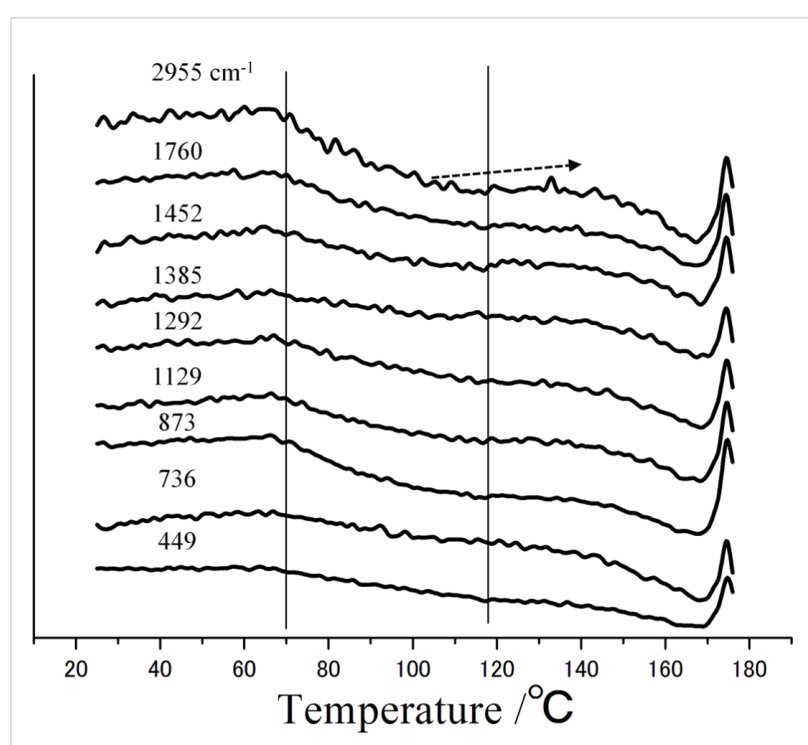

Figure 9: PCA results of PLLA at $2955 \mathrm{~cm}^{-1}, 1760 \mathrm{~cm}^{-1}, 1452 \mathrm{~cm}^{-1}$, $1385 \mathrm{~cm}^{-1}, 1292 \mathrm{~cm}^{-1}, 1129 \mathrm{~cm}^{-1}, 873 \mathrm{~cm}^{-1}, 736 \mathrm{~cm}^{-1}$ and $449 \mathrm{~cm}^{-1}$.

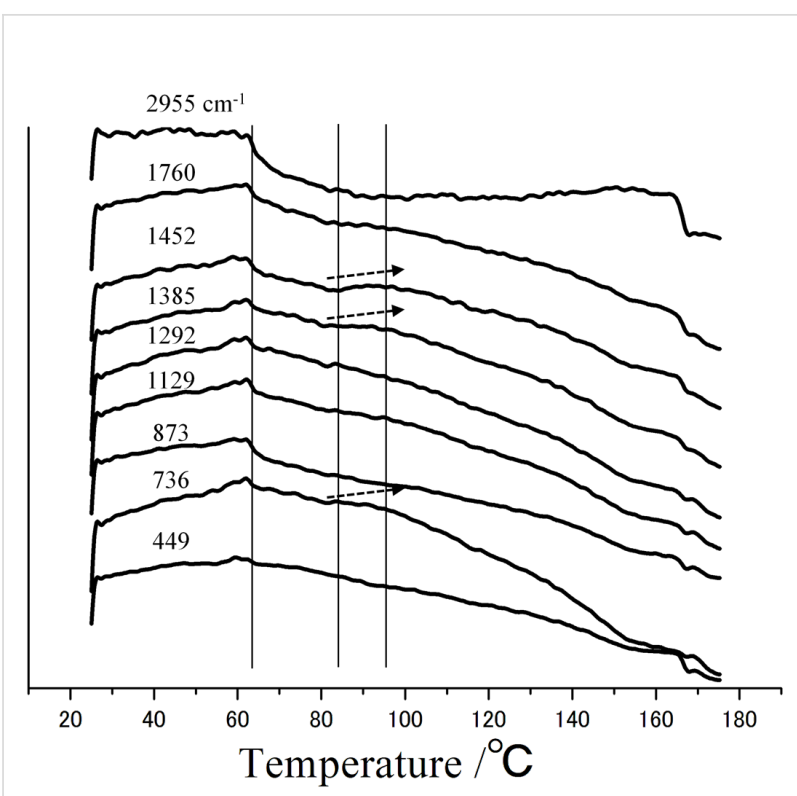

Figure 10: PCA results of PL-MCD83 at $2955 \mathrm{~cm}^{-1}, 1768 \mathrm{~cm}^{-1}$, $1452 \mathrm{~cm}^{-1}, 1385 \mathrm{~cm}^{-1}, 1294 \mathrm{~cm}^{-1}, 1128 \mathrm{~cm}^{-1}, 873 \mathrm{~cm}^{-1}, 736 \mathrm{~cm}^{-1}$ and $449 \mathrm{~cm}^{-1}$.

The peaks at 1385 and $1452 \mathrm{~cm}^{-1}$ increase at approximately $100{ }^{\circ} \mathrm{C}$. The DSC data clearly indicate that cold crystallization occurred at this temperature. Thus, the increase in the peak intensities at $100{ }^{\circ} \mathrm{C}$ corresponds to cold crystallization. This temperature was lower than that for PLLA. These results, along with DSC-Raman measurements, indicate that MeCD addition lowers the $T_{\mathrm{g}}$ and $T_{\mathrm{c}}$. 
The change in peak intensity at $449 \mathrm{~cm}^{-1}$ was similar to those of PLLA peaks. Since MeCD is the main contributor to this peak, this behavior might be affected by the structure of $\mathrm{MeCD}$. At $T_{\mathrm{g}}$, this peak also decreased, which indicates that the mobility of MeCD increased with the segmental motion of PLLA. Above $T_{\mathrm{g}}$, the peak intensity at $449 \mathrm{~cm}^{-1}$ monotonically decreases. The temperature dependence of this peak is similar to that of PLLA over the temperature range observed. Therefore, $\mathrm{MeCD}$ has good affinity for PLLA over a wide range of temperatures. Thus, the analysis of DSC-Raman spectra reveals not only the thermal behavior but also the local structural information of each component with high sensitivity.

\section{Conclusion}

The effect of MeCD addition to PLLA on its physical properties was examined. As revealed through TGA and DSC, the addition of MeCD lowers the $T_{\mathrm{g}}, T_{\mathrm{c}}$, and $T_{\mathrm{m}}$. These results indicate that MeCD prevents PLLA crystallization and increases the amorphous content while enhancing molecular mobility in the amorphous phase. This fact was reflected in the tensile drawing results, in which PL-MCD83 exhibited the largest strain at $60{ }^{\circ} \mathrm{C}$. Since the affinity of MeCD for PLLA is high, MeCD may potentially be used as a plasticizer for PLLA. DSC-Raman measurements showed results similar to those of TGA, DSC, tensile drawing, and DMA. In addition, the detailed behaviors of PLLA and MeCD during heating were observed. DSCRaman offers detailed information regarding the thermal behavior and local structure simultaneously, and is useful for precise temperature-dependent local structure analysis.

\section{Experimental Materials}

$\mathrm{MeCD}$ was purchased from Wako Pure Chemical Ind. (Japan) and used as received. In this $\mathrm{MeCD}$, two methoxy groups per glucopyranose unit were introduced in $\beta$-CD. PLLA (LACEA, Mitsui Chemicals Inc.; $M_{\mathrm{n}}=1.3 \times 10^{5}, M_{\mathrm{w}}=2.6 \times 10^{5}$ ) was used after removing the oligomer and polymerization catalyst by dissolution in chloroform and precipitation in methanol. The precipitated PLLA was dried at $100{ }^{\circ} \mathrm{C}$ for $24 \mathrm{~h}$ in vacuo prior to film preparation. Chloroform and methanol were purchased from Wako Pure Chemical Ind. (Japan) and used as received.

\section{Sample film preparation}

Sample solutions of $1 \mathrm{wt} \%$ PLLA and MeCD were prepared separately by dissolving the requisite amounts of PLLA and $\mathrm{MeCD}$ in chloroform at room temperature. The solutions were mixed and vigorously stirred for $24 \mathrm{~h}$. The PLLA/MeCD chloroform solutions were cast onto a Petri dish and covered with an aluminum foil with holes to allow solvent evaporation at room temperature. The neat PLLA film was prepared with same way. The obtained films were dried in vacuo. Casted films with
$\mathrm{MeCD} / \mathrm{PLLA}$ ratios of 1:1 (50 wt \% PLLA), 1:2 (67 wt \% PLLA), and 1:5 (83 wt \% PLLA) were prepared. The samples were abbreviated as PL-MCD and the wt \% values of PLLA were written after the abbreviated name (e.g., PL-MCD50 for $\mathrm{MeCD} / \mathrm{PLLA}=1: 1)$. The obtained films were used for the experiments; for $\mathrm{MeCD}$, the as received powder was used.

\section{Thermogravimetry/differential thermal analysis (TG-DTA)}

TG-DTA (Perkin-Elmer STA6000) was carried out at $10{ }^{\circ} \mathrm{C} \mathrm{min}-1$ under a nitrogen flow of $60 \mathrm{~mL} \mathrm{~min}^{-1}$ with $5 \mathrm{mg}$ samples placed in an open $\mathrm{Al}_{2} \mathrm{O}_{3}$ pan. For the stability test and accuracy of complex mass ratio, the measurements were carried out from 25 to $800{ }^{\circ} \mathrm{C}$. MeCD was used as received.

\section{Tensile drawing test}

Tensile drawing of samples was carried out at 25, 60, and $100{ }^{\circ} \mathrm{C}$ using a Tensilon RTC-1325A tensile tester (A\&D, Japan). The initial sample length was $10 \mathrm{~mm}$. Tensile drawing measurements were carried out at a cross-head speed of $20 \mathrm{~mm} \mathrm{~min}^{-1}$.

\section{Dynamic mechanical analysis (DMA)}

DMA was conducted from 25 to $140{ }^{\circ} \mathrm{C}$ at $10{ }^{\circ} \mathrm{C} \mathrm{min}-1$ at a frequency of $1 \mathrm{~Hz}$ under a nitrogen atmosphere using DMA861e (Mettler, Toledo). Samples were cut into $25.0 \mathrm{~mm} \times$ $3.0 \mathrm{~mm}$ films.

\section{Constant rate DSC measurements}

For thermal behavior analysis, the constant rate DSC measurements were carried out using a power compensation DSC (Perkin-Elmer DSC 8500). Samples (2 mg) were packed in an $\mathrm{Al}$ pan and the measurements were carried out at $10{ }^{\circ} \mathrm{C} \mathrm{min}^{-1}$ under a nitrogen flow of $20 \mathrm{~mL} \mathrm{~min}{ }^{-1}$. MeCD was used as received.

\section{DSC-Raman measurements}

A power compensation DSC (Perkin-Elmer DSC 8500) connected to a Raman spectrometer (Perkin-Elmer Raman Station 400) through a DSC-Raman interface probe was used. The laser irradiation of the samples and scattering collection from the samples were conducted through glass fibers to minimize the laser irradiation area and to avoid temperature changes. Laser irradiation was configured to $100 \mathrm{~mW}$ for $4 \mathrm{~s}$ with a heat flow amplitude of less than $8 \mathrm{~mW}$ or $0.03{ }^{\circ} \mathrm{C}$ [59]. The collection of Raman spectral data ranged from 3200 to $200 \mathrm{~cm}^{-1}$. DSC-Raman measurements were carried out from 25 to $190{ }^{\circ} \mathrm{C}$ at a heating rate of $2{ }^{\circ} \mathrm{C} \mathrm{min}^{-1}$. The samples $(4 \mathrm{mg})$ were placed in an $\mathrm{Al}$ pan, and a $\mathrm{SiO}_{2}$ disk was placed on the sample to minimize the effect of sample thickness on Raman intensity. MeCD was used as received. 


\section{References}

1. Ikada, Y.; Jamshidi, K.; Tsuji, H.; Hyon, S.-H. Macromolecules 1987, 20, 904. doi:10.1021/ma00170a034

2. Tsuji, H.; Hyon, S.-H.; Ikada, Y. Macromolecules 1991, 24, 5651. doi:10.1021/ma00020a026

3. Tsuji, H.; Hyon, S.-H.; Ikada, Y. Macromolecules 1991, 24, 5657. doi:10.1021/ma00020a027

4. Tsuji, H.; Ikada, Y. Macromolecules 1993, 26, 6918. doi:10.1021/ma00077a032

5. Tsuji, H.; Ikada, Y. Polymer 1999, 40, 6699. doi:10.1016/S0032-3861(99)00004-X

6. Tsuji, H.; Ikada, Y.; Hyon, S.-H.; Kimura, Y.; Kitao, T. J. Appl. Polym. Sci. 1994, 51, 337. doi:10.1002/app.1994.070510216

7. Takasaki, M.; Ito, H.; Kikutani, T. J. Macromol. Sci., Part B: Phys. 2003, 42, 403.

8. Furuhashi, Y.; Kimura, Y.; Yoshie, N.; Yamane, H. Polymer 2006, 47, 5965. doi:10.1016/j.polymer.2006.06.001

9. Tsuji, H.; Nakano, M.; Hashimoto, M.; Takashima, K.; Katsura, S.; Mizuno, A. Biomacromolecules 2006, 7, 3316. doi:10.1021/bm060786e

10. Ishii, D.; Ying, T. H.; Mahara, A.; Murakami, A.; Yamaoka, T.; Lee, W.-k.; Iwata, T. Biomacromolecules 2009, 10, 237. doi:10.1021/bm8009363

11. Sawai, D.; Tamada, M.; Yokoyama, T.; Kanamoto, T.; Hyon, S.-H.; Moon, S. Sen'l Gakkaishi 2007, 63, 1. doi:10.2115/fiber.63.1

12. Sawai, D.; Tamada, M.; Kanamoto, T. Polym. J. 2007, 39, 953. doi:10.1295/polymj.PJ2007038

13. Zhang, J.; Tashiro, K.; Tsuji, H.; Domb, A. J. Macromolecules 2007, 40, 1049. doi: $10.1021 / \mathrm{ma} 061693 \mathrm{~s}$

14. Kakiage, M.; Ichikawa, T.; Yamanobe, T.; Uehara, H.; Sawai, D. ACS Appl. Mater. Interfaces 2010, 2, 633. doi:10.1021/am900896q

15. Uehara, H.; Karaki, Y.; Wada, S.; Yamanobe, T. ACS Appl. Mater. Interfaces 2010, 2, 2707. doi:10.1021/am1005755

16. Yokoyama, Y.; Uehara, H.; Yamanobe, T. Key Eng. Mater. 2013, 543, 71-75. doi:10.4028/www.scientific.net/KEM.534.71

17. Uehara, H.; Nakae, M.; Kanamoto, T.; Zachariades, A. E.; Porter, R. S. Macromolecules 1999, 32, 2761. doi:10.1021/ma981491z

18. Nakae, M.; Uehara, H.; Kanamoto, T.; Ohama, T.; Porter, R. S. J. Polym. Sci., Part B: Polym. Phys. 1999, 37, 1921. doi:10.1002/(SICI)1099-0488(19990801)37:15<1921::AID-POLB16>3. $0 . \mathrm{CO} ; 2-\mathrm{M}$

19. Nakae, M.; Uehara, H.; Kanamoto, T.; Zachariades, A. E.; Porter, R. S. Macromolecules 2000, 33, 2632. doi:10.1021/ma991330a

20. Uehara, H.; Kakiage, N.; Yamanobe, T.; Komoto, T.; Murakami, S. Macromol. Rapid Commun. 2006, 27, 966. doi:10.1002/marc.200600199

21. Kakiage, M.; Yamanobe, T.; Komoto, T.; Murakami, S.; Uehara, H. J. Polym. Sci., Part B: Polym. Phys. 2006, 44, 2455. doi:10.1002/polb.20883

22. Kakiage, M.; Yamanobe, T.; Komoto, T.; Murakami, S.; Uehara, H. Polymer 2006, 47, 8053. doi:10.1016/j.polymer.2006.07.073

23. Uehara, H.; Yoshida, R.; Kakiage, M.; Yamanobe, T.; Komoto, T. Ind. Eng. Chem. Res. 2006, 45, 7801. doi:10.1021/ie060821y

24. Kakiage, M.; Sekiya, M.; Yamanobe, T.; Komoto, T.; Sasaki, S.; Murakami, S.; Uehara, H. Polymer 2007, 48, 7385. doi:10.1016/j.polymer.2007.10.018

25. Morioka, T.; Kakiage, M.; Yamanobe, T.; Komoto, T.; Higuchi, Y.; Kamiya, H.; Arai, K.; Murakami, S.; Uehara, H. Macromolecules 2007, 40, 9413. doi:10.1021/ma071898g
26. Kakiage, M.; Sekiya, M.; Yamanobe, T.; Komoto, T.; Sasaki, S.; Murakami, S.; Uehara, H. J. Phys. Chem. B 2008, 112, 5311. doi:10.1021/jp709782g

27. Kakiage, M.; Uehara, H.; Yamanobe, T. Macromol. Rapid Commun. 2008, 29, 1571. doi:10.1002/marc.200800316

28. He, Y.; Inoue, Y. Biomacromolecules 2003, 4, 1865-1867. doi:10.1021/bm034260v

29. He, Y.; Inoue, Y. J. Polym. Sci., Part B: Polym. Phys. 2004, 42, 3461. doi:10.1002/polb.20213

30. Dong, T.; He, Y.; Zhu, B.; Shin, K.-M.; Inoue, Y. Macromolecules 2005, 38, 7736. doi:10.1021/ma050826r

31. Dong, T.; Shin, K.-m.; Zhu, B.; Inoue, Y. Macromolecules 2006, 39, 2427. doi:10.1021/ma052687j

32. Shin, K.-M.; Dong, T.; He, Y.; Inoue, Y. J. Polym. Sci., Part B: Polym. Phys. 2005, 43, 1433. doi:10.1002/polb.20449

33. Joijode, A. S. Behavior and Properties of Self-Nucleated Poly (ethylene terephthalate) (PET). MS Thesis, North Carolina State University, USA. 2011, p. 41.

34. Shuai, X.; Wei, M.; Porbeni, F. E.; Bullions, T. A.; Tonelli, A. E. Biomacromolecules 2002, 3, 201. doi:10.1021/bm015609m

35. Ohya, Y.; Takamido, S.; Nagahama, K.; Ouchi, T.; Ooya, T.; Katoono, R.; Yui, N. Macromolecules 2007, 40, 6441. doi:10.1021/ma071198b

36. Xie, D. M.; Yang, K. S.; Xun, W. X. Curr. Appl. Phys. 2007, 7 (Suppl. 1), e15. doi:10.1016/j.cap.2006.11.006

37. Mano, J. F. Macromol. Rapid Commun. 2008, 59, 1341. doi:10.1002/marc. 200800180

38. Suzuki, T.; Morikawa, J.; Hashimoto, T.; Buividas, R.; Gervinskas, G.; Paipulas, D.; Malinauskas, M.; Mizeikis, V.; Juodkazis, S. Proc. SPIE 2012, 8249. doi:10.1117/12.907028

39. Suzuki, T.; Takahashi, K.; Uehara, H.; Yamanobe, T. J. Therm. Anal. Calorim. 2013, 113, 1543. doi:10.1007/s10973-013-3098-z

40. Hoidy, W. H.; Ahmad, M. B.; Jaffar Al-Mulla, E. A.; Ibrahim, N. A. B. J. Appl. Sci. 2010, 10, 97. doi:10.3923/jas.2010.97.106

41. Aree, T.; Saenger, W.; Leibnitz, P.; Hoier, H. Carbohydr. Res. 1999, 315, 199. doi:10.1016/S0008-6215(99)00033-6

42. Giordano, F.; Novak, C.; Moyano, J. R. Thermochim. Acta 2001, 380, 123. doi:10.1016/S0040-6031(01)00665-7

43. Ren, Z.; Dong, L.; Yang, Y. J. Appl. Polym. Sci. 2006, 101, 1583. doi:10.1002/app.23549

44. Ljungberg, N.; Wesslén, B. J. Appl. Polym. Sci. 2002, 86, 1227. doi:10.1002/app.11077

45. Labrecque, L. V.; Kumar, R. A.; Davé, V.; MeCarthy, S. P. J. Appl. Polym. Sci. 1997, 66, 1507. doi:10.1002/(SICI)1097-4628(19971121)66:8<1507::AID-APP11>3.0.C O;2-0

46. Ljungberg, N.; Andersson, T.; Wesslén, B. J. Appl. Polym. Sci. 2003, 88, 3239. doi:10.1002/app.12106

47. Mano, J. F.; Gómez Ribelles, J. L.; Alves, N. M.; Salmerón Sanchez, M. Polymer 2005, 46, 8258. doi:10.1016/j.polymer.2005.06.096

48. Turner, J. F., II; Riga, A.; O’Connor, A.; Zhang, J.; Collis, J. J. Therm. Anal. Calorim. 2004, 75, 257. doi:10.1023/B:JTAN.0000017347.08469.b1

49. Cao, X.; Mohamed, A.; Gordon, S. H.; Willett, J. L.; Sessa, D. J. Thermochim. Acta 2003, 406, 115. doi:10.1016/S0040-6031(03)00252-1 
50. Nazhat, S. N.; Kellomäki, M.; Törmälä, P.; Tanner, K. E.; Bonfield, W. J. Biomed. Mater. Res. 2001, 58, 335. doi:10.1002/jbm.1026

51. Tan, H. Y.; Widjaja, E.; Boey, F.; Loo, S. C. J. J. Biomed. Mater. Res., Part B 2009, 91, 433. doi:10.1002/jbm.b.31419

52. Radjabian, M.; Kish, M. H.; Mohammadi, N. J. Appl. Polym. Sci. 2010, 117, 1516. doi:10.1002/app.32046

53. Bertoluzza, A.; Rossi, M.; Taddei, P.; Redenti, E.; Zanol, M.; Ventura, P. J. Mol. Struct. 1999, 480-481, 535-539. doi:10.1016/S0022-2860(98)00734-0

54. Kister, G.; Cassanas, G.; Vert, M. Polymer 1998, 39, 267. doi:10.1016/S0032-3861(97)00229-2

55. Liem, H.; Cabanillas-Gonzalez, J.; Etchegoin, P.; Bradley, D. D. C. J. Phys.: Condens. Matter 2004, 16, 721.

56. Deerwester, S.; Dumais, S. T.; Landauer, T. K.; Furnas, G. W.; Harshman, R. J. Am. Soc. Inf. Sci. 1990, 41, 391. doi:10.1002/(SICI)1097-4571(199009)41:6<391::AID-ASI1>3.0.CO;2-9

57. Aach, J.; Church, G. M. Bioinformatics 2001, 17, 495. doi:10.1093/bioinformatics/17.6.495

58. Yasuniwa, M.; lura, K.; Dan, Y. Polymer 2007, 48, 5398. doi:10.1016/j.polymer.2007.07.012

59. Hart, T. R.; Aggarwal, R. L.; Lax, B. Phys. Rev. B 1970, 1, 638. doi:10.1103/PhysRevB.1.638

\section{License and Terms}

This is an Open Access article under the terms of the Creative Commons Attribution License

(http://creativecommons.org/licenses/by/2.0), which permits unrestricted use, distribution, and reproduction in any medium, provided the original work is properly cited.

The license is subject to the Beilstein Journal of Organic Chemistry terms and conditions:

(http://www.beilstein-journals.org/bjoc)

The definitive version of this article is the electronic one which can be found at: doi:10.3762/bjoc. 10.318 